\title{
Micro-Entrepreneurship: A Sustenance Tool in the Unserved Market
}

\author{
G. Magesh Kuttalam
}

\begin{abstract}
Organisations living in the age of intensified competition make the entire organisation to involve and reinvent their strategies and tactics so as to retain or develop business. In spite of the efforts a large market $\left(3 / 4^{\text {th }}\right.$ of the world population) remains unserved or underserved called as Bottom of Pyramid (BOP). Different experts estimate the size of BOP market as 3-5 trillion USD annually. This untapped potential attracts many of the contemporary marketers. Unfortunately a very few could succeed in their endeavour. Many corporations were unable to reach the set target and could not sustain their mission. The paper attempts to explore the challenges that were in the way to serve the unserved market. The paper ends suggesting that developing micro entrepreneurship pertaining to each village or settlement will help organisations to manoeuvre the challenges.
\end{abstract}

Keywords--- BOP, Sustainability, Unserved Market

\section{INTRODUCTION}

$\mathrm{O}$ RGANISATIONS in these modern days are living in a world where the degree of competition is getting intensified on every passing day. The status quo of every leader or challenger in the market arena is constantly under threat due to this growing competition. Realising the necessity, organisation to withstand competition and pursue their objective of profit/wealth maximisation has started bestowing more importance to marketing and its related activities. Today, marketing is seen as a lifeline activity of any organisations irrespective of its type of product or place of operation. However, the dynamic stature of the market demands a change in strategies and activities constantly. This necessity has pushed the organisation to expand their frontiers of marketing. Hence, innovations in strategies and tactics for application have become a necessary order of the day to sustain their position in the market. Organizations design and execute training module in such a way to sensitise all the employees on the importance of marketing. The contemporary management crew irrespective of its functionality has started to develop a focus generally on market and specifically on customers. Such organisations are able to tide over the difficulties that come across. They always move in order to lookout for opportunities that are a new in the existing market or a new market. Despite the efforts, many times organisations

Dr.G. Magesh Kuttalam, Assistant Professor, Department of Management Studies, Manonmaniam Sundaranar University, Tirunelveli, India.E-mail:mageshkuttalam@gmail.com

DOI: 10.9756/BIJIEMS.3016 fail to cover entire market. The focus is getting limited to few segments and is not even towards the entire market and sometimes is myopic in nature.

\subsection{Un-Served Market}

The focus of the marketers was largely towards the customers belonging to the affluent class of people or those living in the urban society. Less concentration was given towards the people living in poverty or living in rural country side. Unfortunately, the segment neglected by main stream marketers makes up nearly $3 / 4^{\text {th }}$ of the world population. This segment of humanity still remains as an unserved or underserved throughout the world, called as Bottom of Pyramid (BOP) [1] Prahlad, 2006). World Resource Institute (2007) report [2] says that majority of the BOP population are largely dwelling in Africa, Asia, Eastern Europe and Latin America. The table 1 shows the quantum of the population living in the BOP segment and domiciled in various part of the globe. The quantum as per the report approximates to a total of 4 billion globally. The report further says that the people belonging to BOP segment are making out their every single day with less than ' 2 ' USD. This from the point of marketers would give the segment very less buying power and also the demand for products and services. The same was considered to be a strong reason for the neglect of the BOP segment by the marketers.

\subsection{Potentials of BOP Market}

The argument for the neglect of the market holds good if seen BOP customer in isolation. However, the spending power of the segment when collectively estimated gives a mind boggling figure due to the

Table 1:Major Global Regions Hosting BOP Population

\begin{tabular}{|c|c|}
\hline Region & $\begin{array}{c}\text { BOP Population } \\
\text { (in millions) }\end{array}$ \\
\hline Africa & 486 \\
\hline Asia & 2858 \\
\hline Eastern Europe & 254 \\
\hline Latin America & 360 \\
\hline Total (approx.) & 4000 \\
\hline
\end{tabular}

Source: World Resource Institute

quantum of population in the segment. The size of the BOP market amounts to nearly three trillion USD per annum [4 billion $\times \$ 2 \times 365=\$ 3$ trillion (approx...)]. Whereas the Prahlad claims that the purchasing power of the BOP segment amounts to five trillion USD. This testimonies' that BOP market as a whole is a goldmine having huge potential in it. It 
drew the attention of corporate around the world. World resource institute assessed the spending pattern of the BOP

Table 2: Sector Market in BOP Segment

\begin{tabular}{|c|c|}
\hline Sector & $\begin{array}{c}\text { Market Size } \\
\text { (\$ billions) }\end{array}$ \\
\hline Food & 2894 \\
\hline Energy & 433 \\
\hline Housing & 332 \\
\hline Transportation & 179 \\
\hline Health & 158 \\
\hline ICT & 51 \\
\hline Water & 20 \\
\hline
\end{tabular}

segment, table 2 exhibits the major sectors towards which the spending of BOP segment is channelled. Prahlad and Hart (1999) [3] convey that the opportunity at BOP has not been visualised by many corporate due to their core set of assumptions and the practices that are embedded. The duo points out that organisation are under the assumption that "poor are not our target", "poor cannot afford and have no use for products and services that are sold in the developed market" or "The BOP is not important to the long term viability of our business". They opined that this type of bigotry can block the progress of the organisation in the required direction. It has led a shift in the paradigm of the contemporary marketers. Early success of few organisations has inspired the marketers in general and they started to throw their hat upon this segment and a momentum has got set in to tap the potential. The interest of every organisation is upbeat and they attempted to know more on the opportunity that is available for them.

\section{THE STORY @ BOP}

Few organisations who threw their hat on this newly emerging market were also successful. The success came to them because of their innovative product or bundling of their strategies. However, the story that happened at BOP segment was different from the original guestimates and projections. Although the augmented potentials of BOP segment are attractive, the reality is quite different. The momentum gathered in many organisations has lost steam in the way. Many firms that were instantly approaching the market are not successful and have reconsidered their decisions. Karamchandani et al, (2011) [4] after a research found that only minority of corporations that engaged with poor, has created a business with one lakh or more customers in Africa or one million in India. The team of researcher further informed the business fraternity that more than 10 million USD investment made by $P \& G$ in formulating PUR water purification powder for BOP customers, has gone futile and later the company had to turn the product to their philanthropic arm. This episode explains contradictions of the BOP market. At one end there exists a huge potential offering to be tapped and on the other end many firms burnt their fingers in the same BOP market. The perplexity of the marketers on BOP market remains as such. It needs to be demystified. However, the hard truth about BOP market is that it remains unserved or difficult to be served. But many times, it remains underserved.

\subsection{Bop - a Unique Market}

The above complexity exposes the fact that BOP market is different from the general market and is unique in many aspects. However, many times it is difficult for the contemporary marketers who are living in a state of cutthroat competition in the existing market. They may struggle to shift their focus from existing market. The market that is already glutted with products and competitors needed a close watch. Adding to their anguish, the compulsion to improve their top line and bottom line leave them with less time and energy to shed their present pattern of thinking and focus on the new and unexplored BOP market. Sometimes they are also convenient and complacent with the existing market. It requires a strong will to explore the new market and suitable altered strategies for this unserved market. The management if decides strongly to focus on the unserved/underserved market, they need to manoeuvre the unique and complex challenges that are associated with the segment. They need to be clear with the marketing mix required for the segment and divided with the strategic option of broad Vs narrow strategy, economic aspects Vs business prospects in the segment, CSR Vs business scopes and the like.

\section{CHALLENGES @ BOP MARKET}

As seen above the BOP market is unique in nature. The challenges associated with the BOP market are many.

\subsection{BOP's Need and Want}

The products that are served to the BOP at many times are the same that has been provided to the general market and this may not be suitable to the BOP segment. The need and want of BOP market though have a link with the mainstream market is different by its character. This reflects in their need and wants, this may not be similar to that of the existing served market. The BOP market may expect a goods or services suiting to their needs and wants. It in turn requires a modified product, it should be tailor made to the expectation of the BOP market. The modification may include a major modification in the existing product or a minor addition of features. The same product that has been given to the upper half of the market cannot be extended just like that to this market. Organisations that are serious about BOP market have to make the required investment and channel the other necessary resources in the direction.

Need: Investment and resource mobilisation for new set of goods and services that caters the needs of BOP market.

\subsection{BOP Demand and its Mapping}

The demand of BOP is influenced by a set of factors that are not the same as general market. The demand in the BOP market particularly the rural is a derived one, derived from that of the agriculture. Agriculture in turn is highly unpredictable because of its associated features and nature. The poor living in the urban depends largely on the employment of the unorganised sector. The employment generated in both the above case is not consistent with time 
and are quite unpredictable. This inconsistency reflects on the cash that flows into the hands of the BOP segment. It varies from season to season and time to time. Hence, it will be difficult to map or judge the varying purchasing power of the BOP market in similar line with that of the general market. So the demand for the products and services of the BOP remains difficult to predict or it is unpredictable.

Need: Separate indicators to assess the purchasing power and the demand for BOP Market.

\subsection{Heterogeneity of BOP Market}

Adding further to the complexity is the heterogeneous nature of this highly scattered BOP market. The purchasing power within the BOP segment may not be the same and hence the choice of the products may not be the same. It differs from village to village or settlement to settlement. Mapping the needs and wants on this scattered and dispersed market is a real challenge to any organisations. In addition to this the fluctuating nature of the demand of that micro market makes the understanding of dynamics of such market a difficult task. In this scenario it would be difficult to evolve a common program to the BOP market. This makes organisations to think more than once either to enter or continue in the BOP market.

Need: Micro-segmentation focussing on the particular village or settlement is essential.

\subsection{Marketing Program for BOP Behaviour}

The response of the BOP market to the call of companies may be different but that too in the micro level. This will reflect in the product choice, affordability to buy or the message interpretation and the like. The components of the marketing mix such as the product, its assortments, the price, the promotions and the like, designed and fruitful for the general market or commonly for BOP market may not create the required or expected impact upon these micro segments. It needs to be tailor made catering to the needs and want of micro-segment. Due to the change in other component of marketing mix, the distribution policy too has to be redefined considering the micro aspects. Absence of localisation for the local market, organisations may end up in rejection.

Need: Innovation in the marketing mix for the micro BOP market.

\subsection{Economics of Micro Segment}

The difficulty in understanding the dynamics of any single micro segment reduces the interest on the market as a whole for the contemporary markets. The interest further diminishes on the size of micro segment. The size of businesses and profit prospects of micro segments makes it less attractive to the corporates. Organisations can bet only on the economy products whose contribution to the profit margin will be very small when compared to the premium products. It may take a long time for this market to scale up in the value chain and demand a premium product. In order to manage the complexity they will have to identify segments that have a similar pattern so that they can be clustered together.

Need: Organisations have to devise a long term plan and be prepared to wait for getting good returns from BOP market.

\subsection{Separate Organisation for BOP Market}

In order to execute all the above the organisation needs to develop an exclusive team that focuses on this unserved or underserved market. It facilitates better learning and understanding of the market.

Need: Separate organisation and structure that focuses on the BOP market totally.

\section{SUSTENANCE THE VITAL}

It can be understood from the above arguments that the demand, the market, the nature and the behaviour of the BOP market is unique requiring a separate team to look after. The joyful entry into the BOP market may not be sufficient for the organisations to sustain there. Organisations, those willing to capitalise on the potentials of the market, needed to display a difference amidst the contemporary suiting to the need of the market. They are in need to concentrate this market at micro level. It is required to study the market at micro level, design the mix and strategies for micro markets and execute with perfect acceptance of the local segment. Every single micro segment needs to be seen with a rigour as that of a profit centre or an SBU. Failing on the attempt may ruin the short and long run prospects of the organisation because the message both good and bad will spread quickly through the word of mouth communication in these close knitted areas.

It can be concluded that organisations, in order to sustain BOP market, need to focus at micro level. Now the question arises that how to function in this BOP market at micro level? At the same time, the activities that are need for the market have to be executed with required professionalism and higher achievement motivation. The author feels this as a big hurdle for organisation for reaping the success in the BOP market.

\section{MicRo-ENTREPRENEURSHIP: A TOOL FOR SUSTENANCE}

The professional who prepares to work in this market should be able to read the market effectively and do the changes accordingly. He should be capable not only to judge the market but also foresee it in micro level. He should be able to decide then and there and take right decisions at right time with less guidance. For doing so, he/she need to have a deep understanding on the opportunities, sentiments and dynamics of the local market and adjust to it. In the words of Kirzner (1973) [5] such person is termed as entrepreneur who facilitates adjustment to change by spotting opportunities for profitable arbitrage. In short, he should be wearing the hat of an entrepreneur who is capable of taking the challenges and acting independently without much direction. Also in order to meet the requirement at micro level, it is advisable to have personnel from the same locality who possess the knowledge about the market. But such persons with required cognizance 
are seldom available in the market even if available; their exposure may be limited to a few micro segments only. Further, the quantum of such personnel required to cater the BOP market is really huge that may not be possible to obtain in reality. Rather the organisation can follow an alternative path of developing own professional with required entrepreneurial zeal. Institution can identify enthusiastic person at the level of micro segment and provide them with the required training to start and run a business unit. The presence of organisation at the backend may contribute and lift their confidence in their venturing efforts. These industrious entrepreneur partners with a motive to maximize his/her profit, earnestly attempts to solve problems that sprouts in their way. The problems pertaining to the demand, the market and the behaviour of the micro-segment in addition to the logistics can be taken with relative ease by them. He/She will be able to assess the demand and understand the fluctuations in the market. He or she will be in a position to understand the dimension of the need and want of the society where he or she is living. Due to acquaintance in the market these entrepreneur partner may be a good and reliable source of information and can provide the required information needed to arrive at a decision. This would facilitate for penetration and expansion of market for the companies involved and thereby improves the turnover. Thus, developing entrepreneurship in the micro level segment may be a great boon to marketers in order to enter, expand and sustain in the unserved/underserved market.

\section{REFERENCES}

[1] C.K. Prahlad, "The fortune at the bottom of the Pyramid" New Delhi, India: Dorling Kindersley (India) Pvt. Ltd., licensees of Pearson Education in South Asia, 2006.

[2] World Resource Institute, “The next four billion” available at:http//www.wri.org/ business/pubs_description. cfm? Pid = 4142, 2007.

[3] C.K. Prahalad and Stuart. L. Hart, "Strategies for Bottom of Pyramid: Creating Sustainable Development”, available at:http://www.bus.tu.ac.th / usr / wai /xm622/conclude\%20 monsanto/strategies. pdf, 1999.

[4] Ashish Karamchandani, Mike Kubzansky and Nishant Lalwani, "Is the bottom of pyramid really for you?”, Harvard Business Review, 1, March, 2011.

[5] I.M. Kirzner, “Competition and Entrepreneurship”, Chicago: University of Chicago Press, 1973.

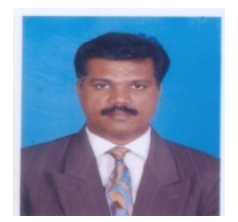

G. Mageshkuttalam was born at Nagercoil, located at the Southern tip of Tamilnadu in India on February 01, 1974. Graduating in chemistry in the year 1994 he took his MBA Programme from Madurai Kamaraj University in the year 1997. The author received his Doctoral Degree in Business Administration from District in 2011.

Manonmaniam Sundaranar University, in Tirunelveli

After serving in the industry for a span of five years the author started his teaching career in the Department of Management Studies, Manonmaniam Sundaranar University, a Tamilnadu state Government University. He then rendered his service in ICFAI group a premium Business School where he headed the campus successfully before coming back to the initial institution. He has authored a book titled Entrepreneurship - The genesis and continuum: A saga of Sivakasi, that describes the growth and development of entrepreneurial culture in the little town Sivakasi. The author also has published many research papers in leading journals and has presented in conferences that are related to his interest. He can be contacted at mageshkuttalam@gmail.com 